IJMMS 28:7 (2001) 427-432

\title{
STATIONARY POINTS FOR SET-VALUED MAPPINGS ON TWO METRIC SPACES
}

\author{
ZEQING LIU, QINGTAO LIU, and SHIN MIN KANG
}

(Received 16 February 2001)

\begin{abstract}
We give stationary point theorems of set-valued mappings in complete and compact metric spaces. The results in this note generalize a few results due to Fisher.

2000 Mathematics Subject Classification. 54H25.
\end{abstract}

1. Introduction and preliminaries. In [2, 4], Fisher and Popa proved fixed point theorems for single-valued mappings on two metric spaces. The purpose of this note is to generalize these results from single-valued mappings into set-valued mappings. In this note, we show stationary point results of set-valued mappings in complete and compact metric spaces.

Let $(X, d)$ and $(Y, \rho)$ be complete metric spaces and $B(X)$ and $B(Y)$ be two families of all nonempty bounded subsets of $X$ and $Y$, respectively. The function $\delta(A, B)$ with $A$ and $B$ in $B(X)$ is defined as follows:

$$
\delta(A, B)=\sup \{d(a, b): a \in A, b \in B\} .
$$

Define $\delta(A)=\delta(A, A)$. Similarly, the function $\delta^{\prime}(C, D)$ with $C$ and $D$ in $B(Y)$ is defined as follows:

$$
\delta^{\prime}(C, D)=\sup \{\rho(c, d): c \in C, d \in D\} .
$$

A sequence of sets in $B(X),\left\{A_{n}: n=1,2, \ldots\right\}$ converges to the set $A$ in $B(X)$ if

(i) each point $a$ in $A$ is the limit of some convergent sequence $\left\{a_{n} \in A_{n}: n=\right.$ $1,2, \ldots\}$

(ii) for arbitrary $\epsilon>0$, there exists an integer $N$ such that $A_{n} \subset A_{\epsilon}$, for $n>N$, where $A_{\epsilon}$ is the union of all open spheres with centers in $A$ and radius $\epsilon$.

Let $T$ be a set-valued mapping of $X$ into $B(X)$. $z$ is a stationary point of $T$ if $T z=\{z\}$. $T$ is continuous at $x$ in $X$ if whenever $\left\{x_{n}\right\}$ is a sequence of points in $X$ converging to $x$, the sequence $\left\{T x_{n}\right\}$ in $B(X)$ converges to $T x$ in $B(X)$. If $T$ is continuous at each point $x$ in $X$, then $T$ is a continuous mapping of $X$ into $B(X)$.

The following Lemmas 1.1 and 1.2 were proved in [1, 3], respectively.

LEMMA 1.1. If $\left\{A_{n}\right\}$ and $\left\{B_{n}\right\}$ are sequences of bounded subsets of a complete metric space $(X, d)$ which converge to the bounded subsets $A$ and $B$, respectively, then the sequence $\left\{\delta\left(A_{n}, B_{n}\right)\right\}$ converges to $\delta(A, B)$.

LEMMA 1.2. Let $\left\{A_{n}\right\}$ be a sequence of nonempty subsets of $X$ and let $x$ be a point of $X$ such that $\lim _{n \rightarrow \infty} \delta\left(A_{n}, x\right)=0$. Then the sequence $\left\{A_{n}\right\}$ converges to the set $\{x\}$. 
2. Stationary point results. Now we prove the following theorem for set-valued mappings.

THEOREM 2.1. Let $(X, d)$ and $(Y, \rho)$ be complete metric spaces. If $T$ is a continuous mapping of $X$ into $B(Y)$ and $S$ is a continuous mapping of $Y$ into $B(X)$ satisfying the inequalities

$$
\begin{gathered}
\delta(S T x, S T y) \leq c \max \left\{\delta(x, y), \delta(x, S T x), \delta(y, S T y), \delta^{\prime}(T x, T y)\right\}, \\
\delta^{\prime}\left(T S x^{\prime}, T S y^{\prime}\right) \leq c \max \left\{\delta^{\prime}\left(x^{\prime}, y^{\prime}\right), \delta^{\prime}\left(x^{\prime}, T S x^{\prime}\right), \delta^{\prime}\left(y^{\prime}, T S y^{\prime}\right), \delta\left(S x^{\prime}, S y^{\prime}\right)\right\},
\end{gathered}
$$

for all $x, y$ in $X$ and $x^{\prime}, y^{\prime}$ in $Y$, where $0 \leq c<1$, then $S T$ has a stationary point $z$ in $X$ and TS has a stationary point $w$ in $Y$. Further $T z=\{w\}$ and $S w=\{z\}$.

Proof. From (2.1) and (2.2), it is easy to see that

$$
\begin{aligned}
\delta(S T A, S T B) & \leq c \max \left\{\delta(A, B), \delta(A, S T A), \delta(B, S T B), \delta^{\prime}(T A, T B)\right\}, \\
\delta^{\prime}\left(T S A^{\prime}, T S B^{\prime}\right) & \leq c \max \left\{\delta^{\prime}\left(A^{\prime}, B^{\prime}\right), \delta^{\prime}\left(A^{\prime}, T S A^{\prime}\right), \delta^{\prime}\left(B^{\prime}, T S B^{\prime}\right), \delta\left(S A^{\prime}, S B^{\prime}\right)\right\},
\end{aligned}
$$

for all $A, B$ in $B(X)$ and $A^{\prime}, B^{\prime}$ in $B(Y)$.

Let $x$ be an arbitrary point in $X$. Define sequences $\left\{x_{n}\right\}$ and $\left\{y_{n}\right\}$ in $B(X)$ and $B(Y)$, respectively, by choosing a point $x_{n}$ in $(S T)^{n} x=X_{n}$ and a point $y_{n}$ in $T(S T)^{n-1} x=Y_{n}$ for $n=1,2, \ldots$. From (2.3) we have

$$
\begin{aligned}
\delta\left(X_{n}, X_{n+1}\right) & =\delta\left(S T X_{n-1}, S T X_{n}\right) \\
& \leq c \max \left\{\delta\left(X_{n-1}, X_{n}\right), \delta\left(X_{n-1}, X_{n}\right), \delta\left(X_{n}, X_{n+1}\right), \delta^{\prime}\left(Y_{n}, Y_{n+1}\right)\right\} \\
& \leq c \max \left\{\delta\left(X_{n-1}, X_{n}\right), \delta^{\prime}\left(Y_{n}, Y_{n+1}\right)\right\} .
\end{aligned}
$$

Similarly,

$$
\delta^{\prime}\left(Y_{n}, Y_{n+1}\right) \leq c \max \left\{\delta^{\prime}\left(Y_{n-1}, Y_{n}\right), \delta\left(X_{n-1}, X_{n}\right)\right\} .
$$

Put $M=\max \left\{\delta\left(x, X_{1}\right), \delta^{\prime}\left(Y_{1}, Y_{2}\right)\right\}$. From the above inequalities, we obtain immediately

$$
\delta\left(X_{n}, X_{n+1}\right) \leq c^{n} M, \quad \delta^{\prime}\left(Y_{n}, Y_{n+1}\right) \leq c^{n} M,
$$

for $n \geq 1$. It follows from (2.2) that

$$
\begin{aligned}
\delta\left(X_{n}, X_{n+r}\right) & \leq \delta\left(X_{n}, X_{n+1}\right)+\cdots+\delta\left(X_{n+r-1}, X_{n+r}\right) \\
& \leq\left(c^{n}+\cdots+c^{n+r-1}\right) M \leq \frac{c^{n}}{1-c} M .
\end{aligned}
$$

Since $c<1$, then $\delta\left(X_{n}, X_{n+r}\right) \rightarrow 0$ as $n \rightarrow \infty$. So

$$
d\left(x_{n}, x_{n+r}\right) \leq \delta\left(X_{n}, X_{n+r}\right) \longrightarrow 0 \quad \text { as } n \rightarrow \infty .
$$

Thus $\left\{x_{n}\right\}$ is a Cauchy sequence. Completeness of $X$ implies that there exists $z$ in $X$ such that $x_{n} \rightarrow z$ as $n \rightarrow \infty$. It follows that

$$
\begin{aligned}
\delta\left(z, X_{n}\right) & \leq \delta\left(z, x_{n}\right)+\delta\left(x_{n}, X_{n}\right) \\
& \leq \delta\left(z, x_{n}\right)+\delta\left(X_{n}, X_{n}\right) \\
& \leq \delta\left(z, x_{n}\right)+2 \delta\left(X_{n}, X_{n+1}\right),
\end{aligned}
$$


which implies that $\delta\left(z, X_{n}\right) \rightarrow 0$ as $n \rightarrow \infty$. Similarly, there exists $w$ in $Y$ such that $y_{n} \rightarrow w$ and $\delta^{\prime}\left(w, Y_{n}\right) \rightarrow 0$ as $n \rightarrow \infty$. Then

$$
\delta^{\prime}\left(w, T x_{n}\right) \leq \delta^{\prime}\left(w, T X_{n}\right)=\delta^{\prime}\left(w, Y_{n+1}\right) .
$$

By the continuity of $T$ and Lemma 1.1 , we have $\delta^{\prime}(w, T z) \rightarrow 0$ as $n \rightarrow \infty$. From Lemma 1.2 it follows that $T z=\{w\}$. Note that

$$
\begin{aligned}
\delta\left(S T z, x_{n}\right) & \leq \delta\left(S T z, X_{n}\right) \\
& \leq c \max \left\{\delta\left(z, X_{n-1}\right), \delta(z, S T z), \delta\left(X_{n-1}, X_{n}\right), \delta^{\prime}\left(T z, T X_{n-1}\right)\right\} .
\end{aligned}
$$

Letting $n$ tend to infinity, we have

$$
\delta(S T z, z) \leq c \max \{\delta(S T z, z), 0\},
$$

which implies that $S T z=\{z\}=S w$. Similarly, we can show that $w$ is a stationary point of TS. This completes the proof of the theorem.

THEOREM 2.2. Let $(X, d)$ be a complete metric space, and let $S$ and $T$ be continuous mappings of $X$ into $B(X)$ and map bounded set into bounded set. If $S$ and $T$ satisfy the inequalities

$$
\begin{gathered}
\delta(S T x, S T y) \leq c \max \{\delta(x, y), \delta(x, S T x), \delta(y, S T y), \\
\delta(x, S T y), \delta(y, S T x), \delta(T x, T y)\}, \\
\delta(T S x, T S y) \leq c \max \{\delta(x, y), \delta(x, T S x), \delta(y, T S y), \\
\delta(x, T S y), \delta(y, T S x), \delta(S x, S y)\},
\end{gathered}
$$

for all $x, y$ in $X$, where $0 \leq c<1$, then $S T$ has a stationary point $z$ and TS has $a$ stationary point $w$. Further $T z=\{w\}$ and $S w=\{z\}$. If $z=w$, then $z$ is the unique common stationary point of $S$ and $T$.

Proof. Let $x$ be an arbitrary point in $X$. Define a sequence of sets $\left\{X_{n}\right\}$ by $T(S T)^{n-1} x=X_{2 n-1},(S T)^{n} x=X_{2 n}$ for $n \geq 1$ and $X_{0}=\{x\}$.

Now suppose that $\left\{\delta\left(X_{n}\right)\right\}$ is unbounded. Then the real-valued sequence $\left\{a_{n}\right\}$ is unbounded, where $a_{2 n-1}=\delta\left(X_{2 n-1}, X_{3}\right), a_{2 n}=\delta\left(X_{2 n}, X_{2}\right)$ for $n \geq 1$ and so there exists an integer $k$ such that

$$
\begin{aligned}
& a_{k}>\frac{c}{1-c} \max \left\{\delta\left(x, X_{2}\right), \delta\left(X_{1}, X_{3}\right)\right\}, \\
& a_{k}>\max \left\{a_{1}, \ldots, a_{k-1}\right\} .
\end{aligned}
$$

Suppose that $k$ is even. Put $k=2 n$. From (2.15) and (2.16) we have

$$
\begin{gathered}
c \delta\left(X_{2 r}, x\right) \leq c\left[\delta\left(X_{2 r}, X_{2}\right)+\delta\left(X_{2}, x\right)\right]<\delta\left(X_{2 n}, X_{2}\right), \\
c \delta\left(X_{2 r-1}, X_{1}\right) \leq c\left[\delta\left(X_{2 r-1}, X_{3}\right)+\delta\left(X_{3}, X_{1}\right)<\delta\left(X_{2 n}, X_{2}\right)\right] .
\end{gathered}
$$

That is,

$$
\delta\left(X_{2 n}, X_{2}\right)>c \max \left\{\delta\left(X_{2 r}, x\right), \delta\left(X_{2 r-1}, X_{1}\right): 1 \leq r \leq n\right\} .
$$


We now prove that the following inequality is true for $m \geq 1$ :

$$
\delta\left(X_{2 n}, X_{2}\right) \leq c^{m} \max \left\{\delta\left(X_{2 r}, X_{2 s}\right), \delta\left(X_{2 r^{\prime}-1}, X_{2 s^{\prime}-1}\right): 1 \leq r, s \leq n, 2 \leq r^{\prime}, s^{\prime} \leq n\right\} .
$$

From (2.13) we have

$$
\begin{aligned}
\delta\left(X_{2 n}, X_{2}\right)= & \delta\left(S T X_{2 n-2}, S T x\right) \\
\leq & c \max \left\{\delta\left(X_{2 n-2}, x\right), \delta\left(X_{2 n-2}, X_{2 n}\right), \delta\left(x, X_{2}\right),\right. \\
& \left.\delta\left(x, X_{2 n}\right), \delta\left(X_{2 n-2}, X_{2}\right), \delta\left(X_{2 n-1}, X_{1}\right)\right\} .
\end{aligned}
$$

It follows from (2.16) and (2.18) that

$$
\delta\left(X_{2 n}, X_{2}\right) \leq c \delta\left(X_{2 n-2}, X_{2 n}\right) .
$$

Now suppose that (2.19) is true for some $m$. From (2.13), (2.14), (2.16), and (2.18) we have

$$
\begin{aligned}
\delta\left(X_{2 n}, X_{2}\right) \leq c^{m} \max \{ & \left.\delta\left(X_{2 r}, X_{2 s}\right), \delta\left(X_{2 r^{\prime}-1}, X_{2 s^{\prime}-1}\right): 1 \leq r, s \leq n, 2 \leq r^{\prime}, s^{\prime} \leq n\right\} \\
\leq c^{m+1} \max \{ & \delta\left(X_{2 r-2}, X_{2 s-2}\right), \delta\left(X_{2 r-2}, X_{2 r}\right), \delta\left(X_{2 s-2}, X_{2 s}\right), \\
& \delta\left(X_{2 r-2}, X_{2 s}\right), \delta\left(X_{2 s-2}, X_{2 r}\right), \delta\left(X_{2 r-1}, X_{2 s-1}\right), \\
& \delta\left(X_{2 r^{\prime}-3}, X_{2 s^{\prime}-3}\right), \delta\left(X_{2 r^{\prime}-3}, X_{2 r^{\prime}-1}\right), \\
& \left.\delta\left(X_{2 s^{\prime}-3}, X_{2 s^{\prime}-1}\right): 1 \leq r, s \leq n, 2 \leq r^{\prime}, s^{\prime} \leq n\right\} \\
\leq c^{m+1} \max \{ & \left.\delta\left(X_{2 r}, X_{2 s}\right), \delta\left(X_{2 r^{\prime}-1}, X_{2 s^{\prime}-1}\right): 1 \leq r, s \leq n, 2 \leq r^{\prime}, s^{\prime} \leq n\right\} .
\end{aligned}
$$

So (2.19) is true for all $m \geq 1$. Letting $m$ tend to infinity, from (2.16) and (2.18) we have $0<\delta\left(X_{2 n}, X_{2}\right) \leq 0$, which is impossible. Similarly, when $k$ is odd, $2 n-1$, say, we also have $0<\delta\left(X_{2 n-1}, X_{3}\right) \leq 0$, which is also impossible. Hence $\left\{\delta\left(X_{n}\right)\right\}$ is bounded.

Let $M=\sup \left\{\delta\left(X_{r}, X_{s}\right): r, s=0,1,2, \ldots\right\}<\infty$. For arbitrary $\epsilon>0$, choose a positive integer $N$ such that $c^{N} M<\epsilon$. Thus for $m, n$ greater than $2 N$ with $m$ and $n$ both even or both odd, from (2.13) and (2.14) we have

$$
\begin{aligned}
\delta\left(X_{m}, X_{n}\right) \leq c \max \{ & \delta\left(X_{m-2}, X_{n-2}\right), \delta\left(X_{m-2}, X_{m}\right), \delta\left(X_{n-2}, X_{n}\right), \\
& \left.\delta\left(X_{m-2}, X_{n}\right), \delta\left(X_{n-2}, X_{m}\right), \delta\left(X_{m-1}, X_{n-1}\right)\right\} \\
\leq c \max \{ & \delta\left(X_{r}, X_{s}\right), \delta\left(X_{r}, X_{r^{\prime}}\right), \delta\left(X_{s}, X_{s^{\prime}}\right): \\
& \left.m-2 \leq r, r^{\prime} \leq m, n-2 \leq s, s^{\prime} \leq n\right\} \\
\leq & c^{N} \max \left\{\delta\left(X_{r}, X_{s}\right), \delta\left(X_{r}, X_{r^{\prime}}\right), \delta\left(X_{s}, X_{s^{\prime}}\right):\right. \\
& \left.m-2 N \leq r, r^{\prime} \leq m, n-2 N \leq s, s^{\prime} \leq n\right\} \\
\leq & c^{N} M<\epsilon .
\end{aligned}
$$

So $\delta\left(X_{2 n}\right)$ and $\delta\left(X_{2 n+1}\right) \rightarrow 0$ as $n \rightarrow \infty$. Take a point $x_{n}$ in $X_{n}$ for $n \geq 1$. Since $d\left(x_{2 n}, x_{2 n+2 p}\right) \leq \delta\left(X_{2 n}, X_{2 n+2 p}\right) \rightarrow 0$ as $n \rightarrow \infty$, hence $\left\{x_{2 n}\right\}$ is a Cauchy sequence. Completeness of $X$ implies that $\left\{x_{2 n}\right\}$ has a limit $z$ in $X$. Note that

$$
\delta\left(z, X_{2 n}\right) \leq \delta\left(z, x_{2 n}\right)+\delta\left(x_{2 n}, X_{2 n}\right) \leq \delta\left(z, x_{2 n}\right)+\delta\left(X_{2 n}\right) .
$$


That is, $\delta\left(z, X_{2 n}\right) \rightarrow 0$ as $n \rightarrow \infty$. Similarly $\left\{x_{2 n+1}\right\}$ converges to some point $w$ in $X$ and $\delta\left(w, X_{2 n+1}\right) \rightarrow 0$ as $n \rightarrow \infty$. Since $\delta\left(w, T X_{2 n}\right)=\delta\left(w, X_{2 n+1}\right)$, by the continuity of $T$ and Lemma 1.1, we have $\delta(w, T z) \rightarrow 0$ as $n \rightarrow \infty$. From Lemma 1.2 it follows that $T z=\{w\}$. In view of (2.13), we obtain that

$$
\begin{aligned}
\delta\left(S T z, x_{2 n}\right) \leq & \delta\left(S T z, X_{2 n}\right) \\
\leq & c \max \left\{\delta\left(z, X_{2 n-2}\right), \delta(z, S T z), \delta\left(X_{2 n-2}, X_{2 n}\right),\right. \\
& \left.\delta\left(z, X_{2 n}\right), \delta\left(X_{2 n-2}, S T z\right), \delta\left(T z, X_{2 n-1}\right)\right\},
\end{aligned}
$$

which implies that

$$
\delta(S T z, z) \leq c \max \{\delta(z, S T z), 0\}
$$

as $n \rightarrow \infty$. Since $c<1, \delta(S T z, z)=0$. Therefore $S T z=\{z\}=S w$ and $T S w=T z=\{w\}$.

Now suppose that $z=w$ and that $z^{\prime}$ is the second common stationary point of $S$ and T. Using (2.1)

$$
\begin{aligned}
\delta\left(z, z^{\prime}\right)= & \delta\left(S T z, S T z^{\prime}\right) \\
\leq & c \max \left\{\delta\left(z, z^{\prime}\right), \delta(z, S T z), \delta\left(z^{\prime}, S T z^{\prime}\right),\right. \\
& \left.\quad \delta\left(z^{\prime}, S T z\right), \delta\left(z, S T z^{\prime}\right), \delta\left(T z, T z^{\prime}\right)\right\} \\
\leq & c \delta\left(z, z^{\prime}\right) .
\end{aligned}
$$

So $z=z^{\prime}$ and this completes the proof of the theorem.

REMARK 2.3. If we use single-valued mappings in place of set-valued mappings in Theorems 2.1 and 2.2, Theorems 2 and 3 of Fisher [2] can be attained.

REMARK 2.4. The following example demonstrates that the continuity of $S$ and $T$ in Theorems 2.1 and 2.2 is necessary.

EXAMPLE 2.5. Let $X=\{0\} \cup\{1 / n: n \geq 1\}=Y$ with the usual metric. Define mappings $S, T$ by $T 0=\{1\}, T(1 / n)=\{1 / 2 n\}$ for $n \geq 1$ and $S=T$. It is easy to prove that all the conditions of Theorems 2.1 and 2.2 are satisfied except that the mappings $S$ and $T$ are continuous. But $S T$ and $T S$ have no stationary points.

Now we give the following theorem for the compact metric spaces.

THEOREM 2.6. Let $(X, d)$ and $(Y, \rho)$ be compact metric spaces. If $T$ is a continuous mapping of $X$ into $B(Y)$ and $S$ is a continuous mapping of $Y$ into $B(X)$ satisfying the following inequalities:

$$
\begin{gathered}
\delta(S T x, S T y)<\max \left\{\delta(x, y), \delta(x, S T x), \delta(y, S T y), \delta^{\prime}(T x, T y)\right\}, \\
\delta^{\prime}\left(T S x^{\prime}, T S y^{\prime}\right)<\max \left\{\delta^{\prime}\left(x^{\prime}, y^{\prime}\right), \delta^{\prime}\left(x^{\prime}, T S x^{\prime}\right), \delta^{\prime}\left(y^{\prime}, T S y^{\prime}\right), \delta\left(S x^{\prime}, S y^{\prime}\right)\right\},
\end{gathered}
$$

for all distinct $x, y$ in $X$ and distinct $x^{\prime}, y^{\prime}$ in $Y$, then $S T$ has a stationary point $z$ and TS has a stationary point $w$. Further $T z=\{w\}$ and $S w=\{z\}$.

Proof. Suppose that the right-hand sides of inequalities (2.28) and (2.29) are positive for all distinct $x, y$ in $X$ and distinct $x^{\prime}, y^{\prime}$ in $Y$. Define the real-valued function 
$f(x, y)$ in $X \times X$ as follows:

$$
f(x, y)=\frac{\delta(S T x, S T y)}{\max \left\{\delta(x, y), \delta(x, S T x), \delta(y, S T y), \delta^{\prime}(T x, T y)\right\}} .
$$

Since $S$ and $T$ are continuous, $f$ is continuous and achieves the maximum value $s$ on the compact metric space $X \times X$. Inequality (2.28) implies $s<1$. That is,

$$
\delta(S T x, S T y) \leq s \max \left\{\delta(x, y), \delta(x, S T x), \delta(y, S T y), \delta^{\prime}(T x, T y)\right\}
$$

for all distinct $x, y$ in $X$. It is obvious that (2.31) is also true for $x=y$. Similarly, there exists $t<1$ such that

$$
\delta^{\prime}\left(T S x^{\prime}, T S y^{\prime}\right) \leq t \max \left\{\delta^{\prime}\left(x^{\prime}, y^{\prime}\right), \delta^{\prime}\left(x^{\prime}, T S x^{\prime}\right), \delta^{\prime}\left(y^{\prime}, T S y^{\prime}\right), \delta\left(S x^{\prime}, S y^{\prime}\right)\right\}
$$

for all $x^{\prime}, y^{\prime}$ in $Y$. So Theorem 2.6 follows immediately from Theorem 2.1.

Now suppose that there exist $z, z^{\prime}$ in $X$ such that

$$
\max \left\{\delta\left(z, z^{\prime}\right), \delta(z, S T z), \delta\left(z^{\prime}, S T z^{\prime}\right), \delta^{\prime}\left(T z, T z^{\prime}\right)\right\}=0,
$$

which implies $\{z\}=\left\{z^{\prime}\right\}=S T z$ and $T z=T z^{\prime}$, a singleton, $\{w\}$, say. Therefore we have $S T z=s w=\{z\}, T S w=T z=\{w\}$. If there exist $w, w^{\prime}$ in $Y$ such that

$$
\max \left\{\delta^{\prime}\left(w, w^{\prime}\right), \delta^{\prime}(w, T S w), \delta^{\prime}\left(w^{\prime}, T S w^{\prime}\right), \delta\left(S w, S w^{\prime}\right)\right\}=0 .
$$

Similarly, we also have $S T z=S w=\{z\}$ and $T S w=T z=\{w\}$. This completes the proof of the theorem.

REMARK 2.7. Theorem 4 of Fisher [2] is a particular case of our Theorem 2.6 if the set-valued mappings in Theorem 2.6 are replaced by single-valued mappings.

ACKNOWLEDGEMENT. This work was supported by Korea Research Foundation Grant (KRF-2000-DP0013).

\section{REFERENCES}

[1] B. Fisher, Common fixed points of mappings and set-valued mappings, Rostock. Math. Kolloq. (1981), no. 18, 69-77. MR 83e:54041. Zbl 0479.54025.

[2] _ Related fixed points on two metric spaces, Math. Sem. Notes Kobe Univ. 10 (1982), no. 1, 17-26. MR 83k:54050. Zbl 0501.54032.

[3] B. Fisher and S. Sessa, Two common fixed point theorems for weakly commuting mappings, Period. Math. Hungar. 20 (1989), no. 3, 207-218. MR 91c:54055. Zbl 0643.54041.

[4] V. Popa, Fixed points on two complete metric spaces, Zb. Rad. Prirod.-Mat. Fak. Ser. Mat. 21 (1991), no. 1, 83-93. CMP 1158 447. Zbl 0783.54040.

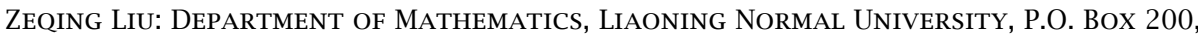
DALIAN, LIAONING 116029, CHINA

E-mail address: zeqing 7 iu@sina.com.cn

Qingtao LiU: DePARTMENT OF MATHEMATICS, LIAONING NORMAL UNIVERSITY, P.O. BOX 200, DALIAN, LIAONING 116029, CHINA

Shin Min Kang: Department of Mathematics, Gyeongsang National University, CHINJU 660-701, KoREA

E-mail address: smkang@nongae.gsnu.ac.kr 


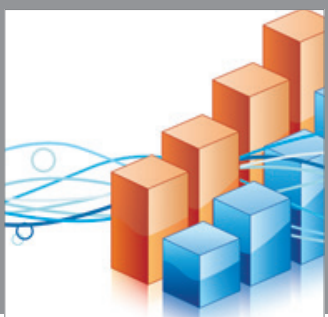

Advances in

Operations Research

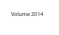

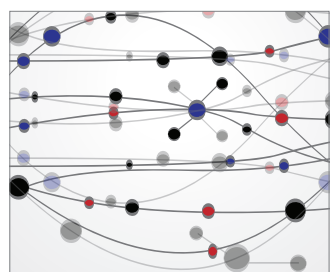

\section{The Scientific} World Journal
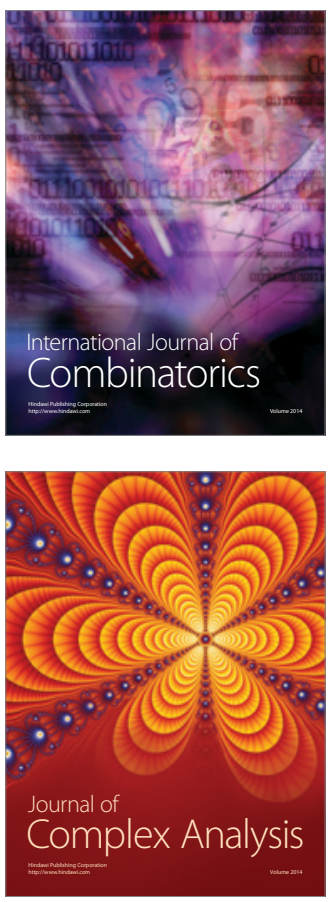

International Journal of

Mathematics and

Mathematical

Sciences
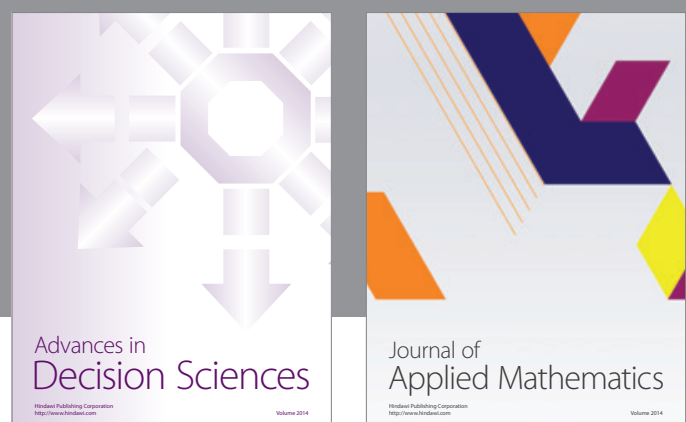

Journal of

Applied Mathematics
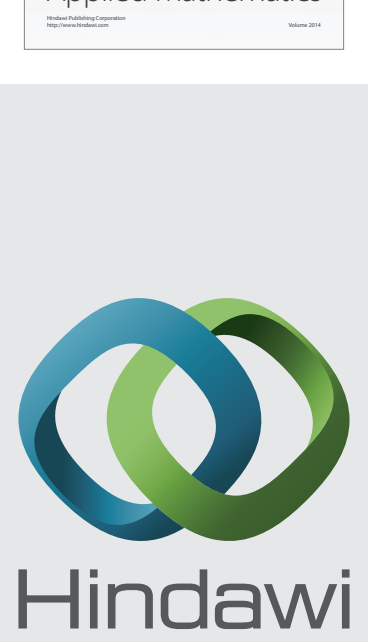

Submit your manuscripts at http://www.hindawi.com
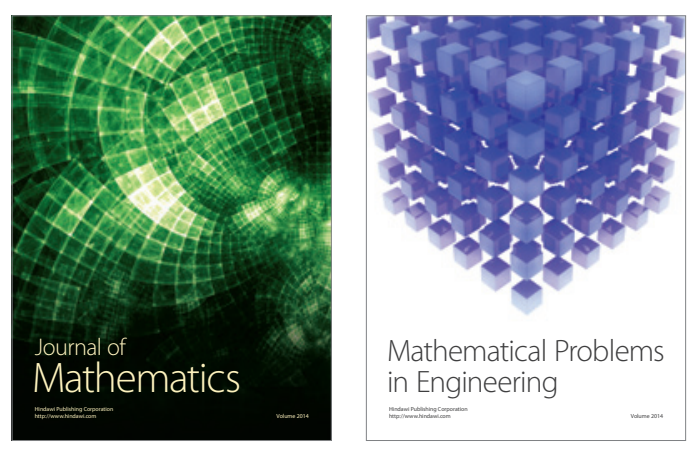

Mathematical Problems in Engineering
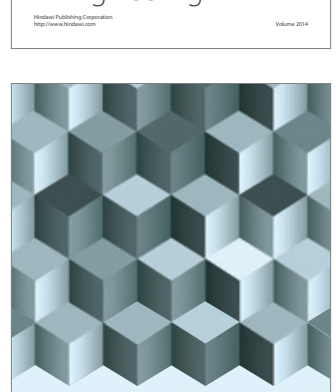

Journal of

Function Spaces
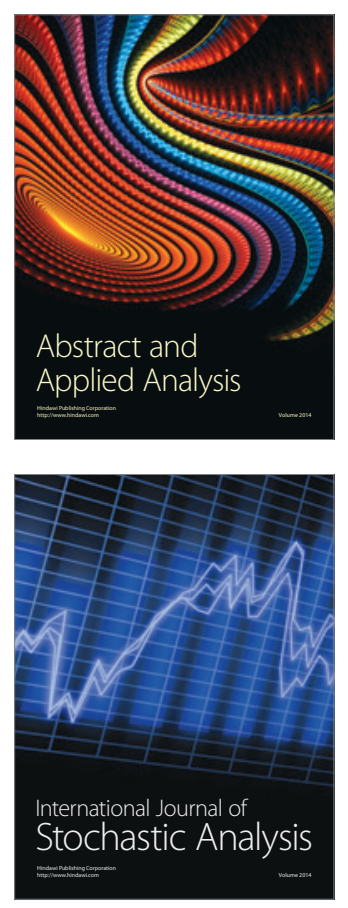

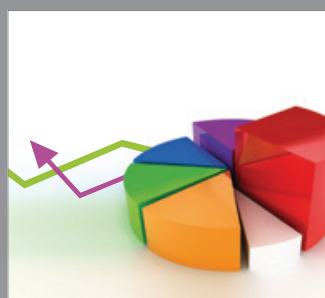

ournal of

Probability and Statistics

Promensencen
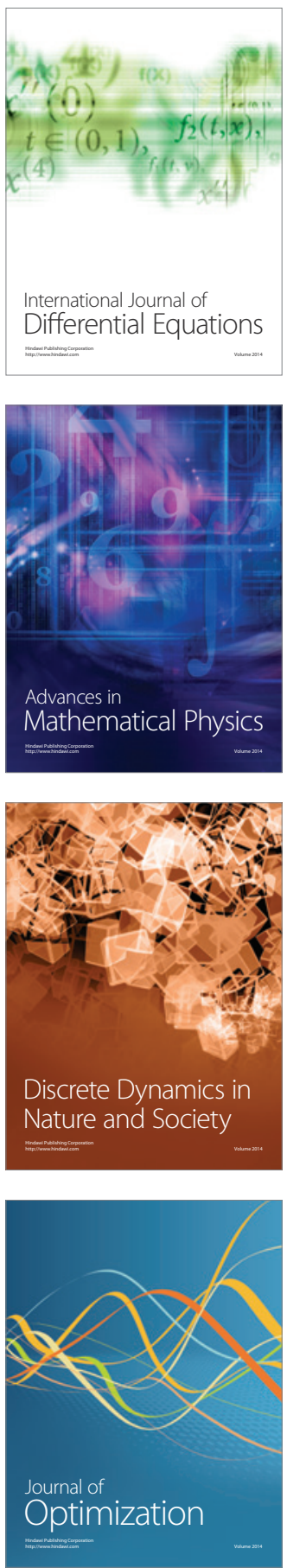